\title{
Influence of prey detection on capture success for the ctenophore Mnemiopsis leidyi feeding upon adult Acartia tonsa and Oithona colcarva copepods
}

\author{
J. H. Costello*, R. Loftus, R. Waggett** \\ Biology Dept., Providence College, Providence, Rhode Island 02918-0001, USA
}

\begin{abstract}
Although the lobate ctenophore Mnemiopsis leidyi is known to be an important copepod predator, the mechanistic basis for its predatory success is not well understood. We directly observed and recorded predation by free-swimming $M$. leidyi ctenophores on Acartia tonsa and Oithona colcarva copepods ( $\mathrm{n}=349$ encounters, 25 different ctenophores) in the laboratory using videographic methods. Overall capture success was relatively high $(74 \%)$ following copepod contact with $M$. leidyi. However, average retention of copepods initially contacting the interior surfaces of the oral lobes (the major capture sites) was considerably lower $(34 \%)$. Average retention was low because copepods most frequently collided head-first with the oral lobes and bounced away without being captured. Escape success for copepods declined rapidly during ensuing contacts, and most captures $(57 \%)$ involved multiple contacts within an encounter. Our most novel finding was that almost half $(49 \%)$ of the encounters involved alterations of oral lobe positions which preceded, or anticipated, actual contact with a copepod. Anticipatory responses were cued to fluid disturbances created by swimming copepods. Anticipation of prey contact allowed ctenophores to shift oral lobe positions and reduce copepod escape avenues, thereby increasing the number of contacts per encounter and significantly increasing capture efficiency.
\end{abstract}

KEY WORDS: Foraging · Escape · Hydrodynamic cues · Anticipation · Behavior - Selection · Ambush

\section{INTRODUCTION}

The capacity of the lobate ctenophore Mnemiopsis leidyi to rapidly capture and ingest copepod prey (Bishop 1967, Reeve et al. 1978, Kremer 1979) enables it to substantially affect planktonic community structure (Burrell \& Van Engel 1976, Mountford 1980, Deason \& Smayda 1982). However, no mechanistic explanation has been described for the success of $M$. leidyi in capturing adult copepod prey. This success is surprising in light of the relatively low retention rates of copepods contacting the oral lobes. The inner surfaces of the oral lobes are the primary capture surfaces of adult copepods, but less than half of the contacts with adult Acartia tonsa result in prey retention (Waggett \&

\footnotetext{
-E-mail: costello@providence.edu

- Present address: Marine Science Institute, University of Texas at Austin, Port Aransas, Texas 78373-1267, USA
}

Costello 1999). Failure to retain a copepod can be costly to a ctenophore because copepod escape velocities are rapid, often exceeding 350 bodylengths $\mathrm{s}^{-1}$ (Strickler 1975). How can such elusive prey be captured by a lower metazoan such as $M$. leidyi, which possesses only moderately effective capture surfaces and the limited response capabilities of a nerve net system (Hyman 1940)?

The goal of this research was to determine the critical factors affecting capture success of Mnemiopsis leidyi preying upon late stage copepods. Our approach was to quantitatively examine the encounter process between lobate stage $M$. leidyi and the 2 seasonally dominant copepod species which co-occur with $M$. leidyi in Narragansett Bay, Rhode Island, USA (Hulsizer 1976). Oithona colcarva, a cyclopoid copepod, is an ambush forager on microzooplankton and swims infrequently, primarily lying motionless in the water column until attacking prey. Acartia tonsa is a calanoid 
copepod which swims with a 'hop and sink' pattern characteristic of many calanoids. Comparative examination of these 2 species was intended to provide insight into the influence of copepod behavioral patterns on the capture success of $M$. leidyi.

\section{METHODS}

Collection and maintenance of experimental organisms. Mnemiopsis leidyi and copepod zooplankton were collected as needed from July to October 1995 from Narragansett Bay in Barrington, Rhode Island, either by hand dipping with small jars (M. leidyi) or in a $333 \mu \mathrm{m}$ mesh plankton net (copepods). All plankton were maintained in $0.22 \mu \mathrm{m}$ filtered seawater at $21^{\circ} \mathrm{C}$ in $25 \mathrm{l}$ vessels in the laboratory at Providence College, Providence, Rhode Island, until used for experimental work. Ctenophores were used for experiments within 72 h of collection.

Microvideography. Standard rate video recordings (SVHS) using an unfiltered halogen backlit optical system (Costello \& Colin 1994) were used to detail movements of ctenophores, prey and tracer particles. A field counter labeled each sequential video frame (1/60 s per field) in order to provide temporal information. Spatial characteristics of the optical field were determined from scale bars periodically included in the recordings. Interference from motions in the unmeasured third dimension was minimized by limiting the image depth of field and by selecting particles in the focal plane. The optical system provided clear illumination of particles as well as their movements relative to the ctenophore.

Encounter analysis. While encounter experiments involving free-swimming ctenophores and copepod prey needed to be of short enough duration to avoid both ctenophore satiation and significant decreases in prey density, they needed to be of long enough duration to include multiple prey encounters by individual ctenophores. Ctenophores were selected for a fairly uniform size $(0.8$ to $1.6 \mathrm{~cm}$, mean $=1.1, \mathrm{SD}=0.1 \mathrm{~cm})$ in order to limit ctenophore size as an influential variable. Interactions between free-swimming Mnemiopsis lei$d y i$ and copepods were videotaped in $300 \mathrm{ml}$ vessels filled to $200 \mathrm{ml}$ with $0.2 \mu \mathrm{m}$ filtered seawater. Initial video recording of ctenophores began in filtered seawater. After 1 to 2 min, a combination of approximately 50 individuals (late stage copepodites and adults) of both Acartia tonsa and Oithona colcarva was added to each vessel. Video segments in which ctenophores and copepods interacted were analyzed frame by frame. Stages in the predation cycle were related in a sequence adapted from a variety of sources (Gerritsen \& Strickler 1977, Madin 1988):

$$
\begin{aligned}
& \qquad \\
& \text { Encounter } \rightarrow \text { Contact } \rightarrow \text { Capture } \rightarrow \text { Ingestion } \\
& \qquad \quad \text { Escape } \quad \text { L Escape }
\end{aligned}
$$

Patterns of copepod-ctenophore encounters were tabulated according to this sequence using the termi-

\begin{tabular}{|c|c|}
\hline Variable & Description \\
\hline Encounter & $\begin{array}{l}\text { Interaction between ctenophore and copepod within the encounter zone, initiated either by direct } \\
\text { contact between ctenophore and copepod or by an anticipatory response (e.g. oral lobe folding) by } \\
\text { ctenophore prior to contact with copepod. The encounter zone was defined as the area bounded on } \\
\text { the sides by the interior lobes of the ctenophore and extending anterior to the lobes for } 3 \mathrm{~mm} \text { (approx- } \\
\text { imately } 2 \text { Acartia tonsa bodylengths). Encounters terminated in either an escape from the encounter } \\
\text { region or capture of the copepod by the ctenophore }\end{array}$ \\
\hline Encounter origin & $\begin{array}{l}\text { Means of encounter initiation; either flow entrainment or self-propelled swimming by the copepod. } \\
\text { Copepod motion relative to surrounding flow was readily confirmed by visually comparing copepod } \\
\text { velocities with those of surrounding particles entrained within flow fields }\end{array}$ \\
\hline Contact & $\begin{array}{l}\text { Physical collision of predator and prey bodies. An encounter could entail multiple contacts if the } \\
\text { copepod was not retained and collided with another portion of the ctenophore's capture surfaces. } \\
\text { Contacts with exterior portions of the ctenophore's body (e.g. lobe exterior) were not recorded as } \\
\text { contacts because these could not result in capture and were outside the encounter zone }\end{array}$ \\
\hline Escape & $\begin{array}{l}\text { Evasion of capture by a copepod after encounter with a ctenophore }{ }_{i} \text { the copepod must have left the } \\
\text { encounter zone. Contact was not required }\end{array}$ \\
\hline Capture & Copepod subdued and consumed by ctenophore \\
\hline Anticipatory response & Lobe or auricle motion of ctenophore in response to copepod prior to actual contact \\
\hline Prey motion & Motion of copepod prey in vicinity of the ctenophore prior to contact \\
\hline Number of contacts & Number of contacts between the ctenophore and copepod during an encounter \\
\hline Encounter outcome & Capture or escape of a copepod as a result of an encounter \\
\hline
\end{tabular}
nology and criteria described in Table 1.

Table 1. Patterns of copepod-ctenophore encounters 
Individual ctenophore variability. Generalizations about overall interaction patterns are most useful if variability within and between individual ctenophores during interaction patterns is not of major importance. In order to assess intra-individual variability over the time course of our observations, we divided the observation periods of individual ctenophores into two 12 min intervals. These consecutive periods were then compared as repeated measures of predation efficiency for individual ctenophores. Inter-individual variability was assessed by using the repeated measures as replicates for comparison between individual ctenophores. Individual ctenophores used for comparisons fit 2 criteria: they had to have been in full, focused view for the majority of a 24 min viewing period, and they had to have a minimum of 2 encounters during each half of the $24 \mathrm{~min}$ period in order to allow for intra-individual comparison. These criteria were met by 13 of the 25 ctenophores. Not all the ctenophores were acceptable for comparison because some ctenophores swam out of the center of the viewing vessel towards the vessel walls and closed their lobes temporarily. These periods were excluded from encounter analysis The 13 individuals used for comparison were those that could be followed for a full, contiguous 24 min with virtually every prey encounter quantified. A 24 min duration was chosen because, although several individuals were observed for $30 \mathrm{~min}$ or more, most useful observations lasted less than this, and $24 \mathrm{~min}$ was a period that included enough individuals for an adequate sample size. Acartia tonsa were chosen as the prey type for comparison because all ctenophores commonly encountered this prey type, whereas Oithona colcarva were less commonly encountered and, for some ctenophores, not encountered during one of the two $12 \mathrm{~min}$ periods.

The 2 variables used for comparison, retention and capture efficiency, were defined as:

$$
\begin{aligned}
& \text { Retention efficiency }=\frac{\text { no. of captures }}{\text { no. of contacts }} \times 100 \\
& \text { Capture efficiency }=\frac{\text { no. of captures }}{\text { no. of encounters }} \times 100
\end{aligned}
$$

By definition, the 2 efficiencies were different when encounters involved more than 1 contact. Retention efficiency quantifies the effectiveness with which a capture surface retains prey at contact. In contrast, capture efficiency is an indicator of overall outcome of ctenophore copepod encounters, regardless of the number of contacts occurring during the encounters. Therefore, retention efficiency may be viewed as a measure of the mechanical efficiency of the predator capture surfaces, whereas capture efficiency is a measure of overall predatory success that integrates
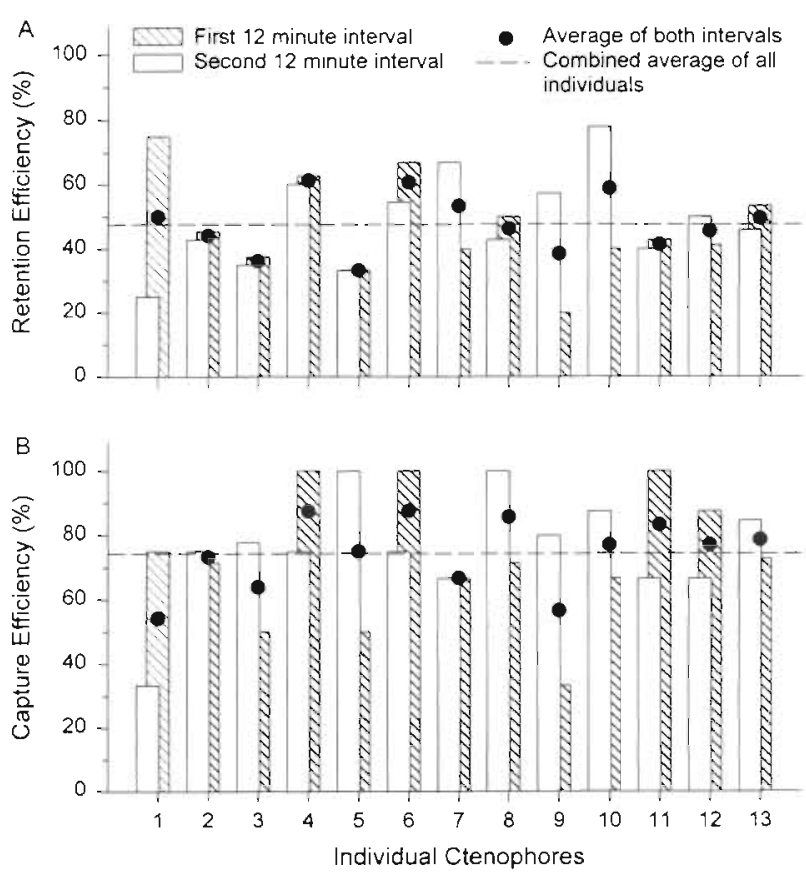

Fig. 1 Intra-specific variation in feeding efficiency of Mnemiopsis leidyi. Retention and capture efficiencies of individual M. leidyi feeding on the copepod Acartia tonsa were measured during 2 successive 12 min intervals

ctenophore and copepod behavioral responses with the mechanical efficiency of the capture surfaces.

\section{RESULTS}

\section{Intra- and inter-individual variability in predation success}

There was no evidence that either satiation or differences between individual ctenophores affected predator-prey interactions during the experiments. Neither retention nor capture efficiency of individual ctenophores differed consistently between the early and late sample periods (Fig. 1; repeated measures ANOVA, $p=0.784$ for retention efficiency, $p=0.701$ for capture efficiency). Likewise, no systematic patterns of interindividual variation affected predator-prey interactions (ANOVA, $\mathrm{p}=0.748$ and 0.836 for retention and capture efficiencies, respectively).

The absence of any consistent, significant variation either within or between individual ctenophores indicated that unique traits of individual ctenophores were not the predominant factors influencing the outcomes of prey encounters. Therefore, data from all individuals were grouped together in order to determine emergent patterns common to all the ctenophores observed. 


\section{Variations in encounter mechanisms between prey}

The importance of ciliary flow fields for entraining prey and causing contact with ctenophores depended upon the prey type. Acartia tonsa most commonly $(82 \%)$ swam into the outstretched lobes of ctenophores (Figs. 2 \& 3). A minority (18\%, Fig. 2) of their encounters with ctenophores were initiated by entrainment in auricular flow fields. In contrast, the smaller size and low swimming activity of Oithona colcarva resulted in their frequent (95\%) encounter via entrainment within auricular flow fields (Fig. 2). The 2 copepods also swam differently during an encounter. Whereas $A$. tonsa escape jumps often carried them more than $1.0 \mathrm{~cm}$ distance, $O$. colcarva typically made numerous small hops within the ctenophore flow field, but these were only several mm distance each and generally did not carry them out of the ctenophore flow field (Fig. 4). As a result, individual

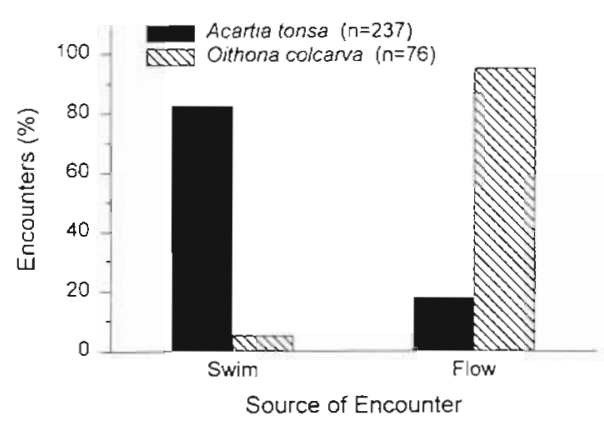

Fig. 2. Proportion of copepod (Acartia tonsa, Oithona colcarval encounters with the ctenophore Mnemiopsis leidyi, attributed to either a self-propelled approach by the copepod (Swim) or entrainment of the copepod in the auricular flow field (Flow)

$O$. colcarva frequently swam against the flow field for several seconds before contacting a ctenophore capture surface.

\subsection{0}

1.90

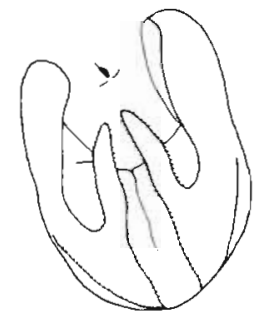

2.00

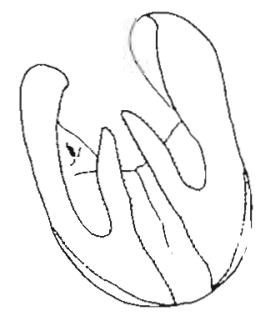

2.53

5.87

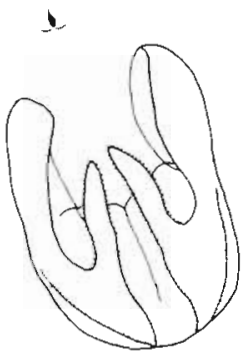

Fig. 3. Encounter of the ctenophore Mnemiopsis leidyi with the copepod Acartia tonsa. Successive frames (left to right) represent copepod position and orientation changes during the time course of the encounter. Cumulative time in seconds at which each frame occurred is listed above each frame. The copepod swam from the surrounding fluid $(0.00 \mathrm{~s})$ into the inter-lobe space (1.90 s) before jumping into the inner oral lobe surface (ventral contact) where it was retained (2.00 s). The oral lobe then curled over (2.53 s) and completely enveloped the copepod (5.87 s)

0.00

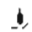

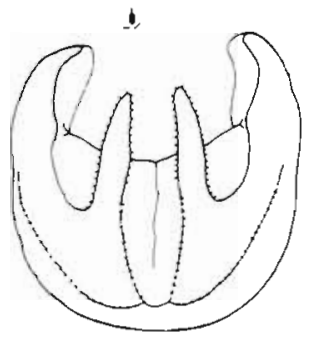

2.37

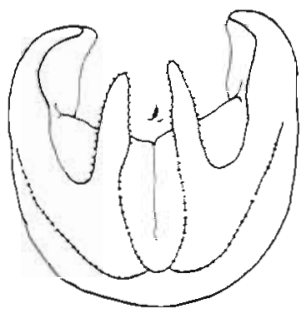

6.77

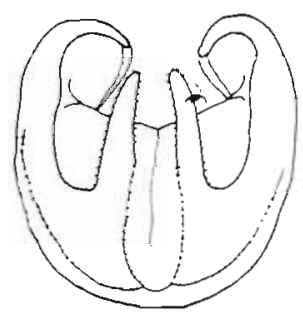

7.63

9.40

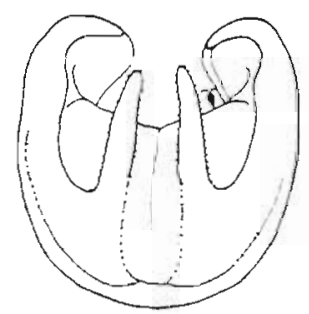

Fig. 4. Encounter of the ctenophore Mnemiopsis leidyi with the copepod Oithona colcarva. Successive frames (left to right) represent copepod position and orientation changes during the time course of the encounter. Cumulative time in seconds at which each frame occurred is listed above each frame. The copepod was initially entrained in the auricular flow (0.00 s). The oral lobes began to curl $(2.37 \mathrm{~s})$ in anticipation of contact. Several contacts, each followed by small escape jumps $(6.77,7.63 \mathrm{~s}), 0 \mathrm{ccurred}$ before the final contact resulting in capture $(9.40 \mathrm{~s})$. Once enmeshed and retained on the inside surface of the oral lobe, the copepod was transported by the lobe to the oral groove 


\section{Influence of prey orientation on predation success}

Most of the 543 contacts we observed occurred either too rapidly or with insufficient spatial definition to clearly resolve the orientation of the prey to the ctenophore's body surface at the time of contact. However, a portion of the contacts $31 \%$ for Acartia tonsa and $12 \%$ for the smaller Oithona colcarvaj occurred with sufficient temporal and spatial resolution to determine copepod body orientation at the time of, or immediately after, contact.

Copepod body orientations varied considerably during contact with ctenophores (Fig. 5A). Both copepod species most frequently swam into the ctenophore head-first, i.e. the anterior portion of the cephalothorax made contact first. Ventral contacts (usually involved the thoracic swimming limbs) were the second most frequent for Acartia tonsa and ranked third in frequency for Oithona colcarva. Dorsal (the upper region of the cephalosome) and posterior (urosomal) contacts were the least frequent for $A$. tonsa, together representing only $16 \%$ of the observed contacts. Posterior contacts were more common for $O$. colcarva than $A$. tonsa, because $O$. colcarva entrained in the auricular flow (Fig. 4) often oriented against the flow and thus 'backed' into ctenophore tentillae with elongate urosomal spines as the copepods were transported towards the auricles. A. tonsa has less pronounced urosomal spines and were less frequently transported by auricular currents than $O$. colcarva. This resulted in fewer $A$. tonsa 'backing' into tentillae.

Copepod body orientation affected retention efficiency (Fig. 5B). Retention was highest for ventral contacts (Acartia tonsa 98\%; Oithona colcarva 100\%) and lowest for anterior contacts (A. tonsa $7 \% ; 0$. colcarva $20 \%$ ). Posterior contacts, often involving the ctenophore's tentillae, also had high retention efficiencies (A. tonsa $75 \%$; O colcarva $80 \%$ ). Dorsal contacts were moderately efficient for $A$. tonsa $(53 \%)$, but were not observed for $O$. colcarva. Retention rates of anterior contacts were significantly lower $\left(\chi^{2}, p<0.05\right.$ for all comparisons within a prey species) than other orientations for both prey species.

Capture rates reflected the retention efficiencies of various contact orientations (Fig. 5C). Although anterior contacts were the most frequent, their low retention rates resulted in a significantly $\left(\chi^{2}, p<0.001\right.$ for Acartia tonsa, $\mathrm{p}=0.012$ for Oithona colcarva) lower contribution to the capture rate than any other orientation. For example, $48 \%$ of $A$. tonsa contacts but only $7 \%$ of the observed captures were anterior oriented. Likewise, ventral contacts resulted in a disproportionately high number of captures. Although ventral contacts accounted for only $36 \%$ of the total $A$. tonsa contacts examined, ventral
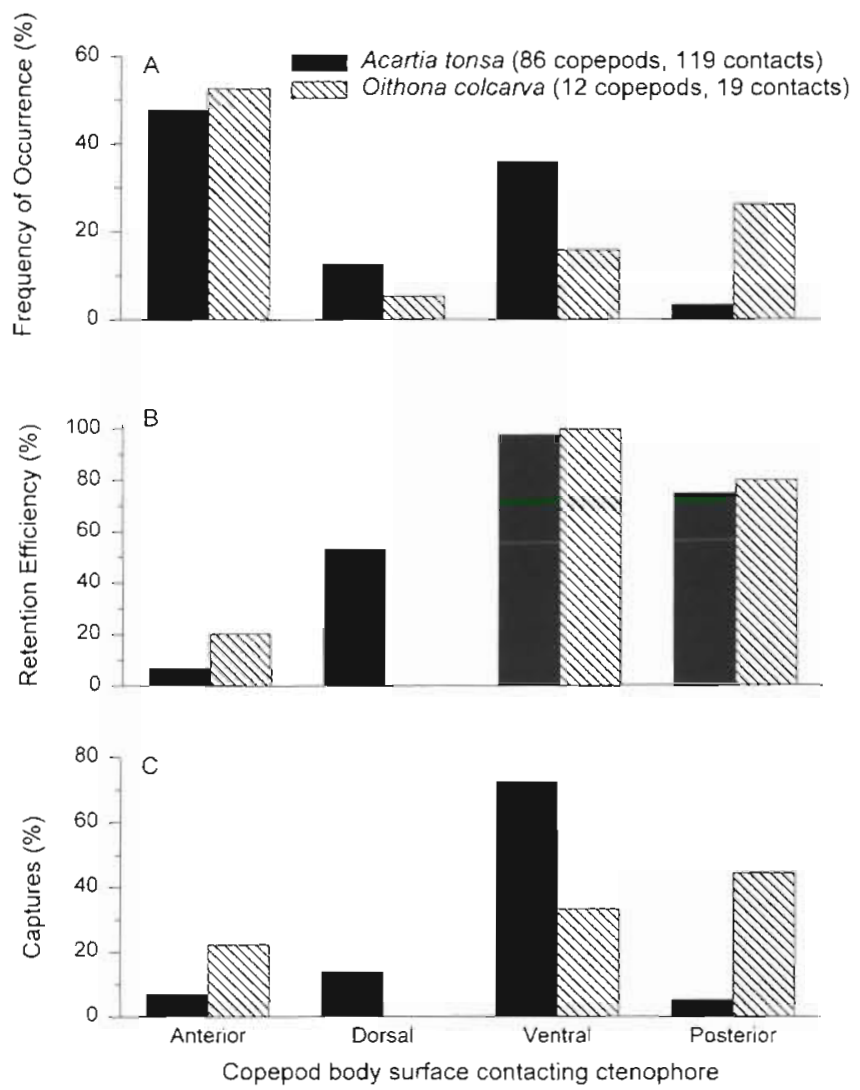

Fig. 5. Relationships between (A) frequencies of specific contact orientations, (B) retention efficiency and (C) the proportions of prey captures by the ctenophore Mnemiopsis leidyi encountering the copepods Acartia tonsa and Oithona colcarva

contacts represented $72 \%$ of the captures. Posterior contacts also contributed a disproportionately high number of captures of $O$. colcarva (Fig. 5C). The pattern common to both copepod species was that ventral contacts resulted in a disproportionately high number of captures while anterior contacts resulted in a disproportionately low number of captures.

The combined retention efficiencies of all orientations in this subsample (Acartia tonsa $48 \%$; Oithona colcarva $47 \%$ ) were not significantly different $\left(\chi^{2}, p=0.345\right.$ for $A$. tonsa, $\mathrm{p}=0.467$ for $O$. colcarva) from the overall retention efficiencies for the total samples of each species ( $A$. tonsa $44 \%$; O colcarva $39 \%$ ). Therefore, although contact orientation was not recorded for most of the contacts, overall retention efficiency for the orientation data subsample resembled that of the total data set.

\section{Influence of the number of contacts within an encounter on predation success}

The number of contacts occurring within an encounter significantly influenced the probability of suc- 



Fig. 6. Contact-specific breakdown of encounter statistics for the copepods Acartia tonsa and Oithona colcarva encountering the ctenophore Mnemiopsis leidyi. Each variable, (A) frequency of occurrence, (B) escape frequency, (C) retention efficiency and (D) capture efficiency, is listed for each successive contact in an encounter

cessful copepod capture during an encounter. Single contact encounters were the most frequent type of encounter (Acartia tonsa 58\%, Oithona colcarva 46\%; Fig. 6A) but contributed a disproportionately high fraction of copepod escapes ( $88 \%$ for both $A$. tonsa and $O$. colcarva; Fig. 6B) because of the relatively low retention efficiency of initial contacts between copepods and ctenophores (A. tonsa 33\%, O. colcarva $27 \%$, Fig. $6 \mathrm{C}$ ). The majority of captures (A. tonsa $54 \%, O$. colcarva $65 \%$ ) resulted from multiple contact encounters. In these cases, multiple contacts occurred because the copepod broke free from the initial contact but subsequently collided with a different portion of the ctenophore's body. Escape rates were lower in multiple contact encounters than in single contact encounters (Fig. 6B), and this was reflected in higher retention rates of multiple contact encounters for both species (Fig. 6C). Retention efficiency increased significantly for encounters having 2 contacts in comparison to those having only a single contact $\left(\chi^{2}, p=0.001\right.$ for $A$. tonsa, $\mathrm{p}=0.022$ for $O$. colcarva). Although absolute values fluctuated, there were no significant differences in the retention efficiencies of either copepod species for encounters with 3 or more contacts $\left(\chi^{2}, p>0.15\right.$ for all comparisons within each prey species). No copepod of either species escaped when encounters involved 4 or more contacts.

One result of differential retention rates between single and multiple contacts was that capture efficiencies were higher for multiple than for single contact encounters (Fig. 6D). Capture efficiencies of single contact encounters (Acartia tonsa $57 \%$, Oithona colcarva $60 \%)$ were significantly lower $\left(\chi^{2}, \mathrm{p}<0.001\right.$ for A. tonsa, $\mathrm{p}=0.004$ for $O$. colcarva) than for 2 -contact encounters (A. tonsa $91 \%, O$. colcarva $95 \%$ ). Capture efficiencies for all multiple contact encounters of both prey species were over $90 \%$, and there were no significant differences between multiple contact capture efficiencies for either species $\left(\chi^{2}, p>0.5\right.$ for all comparisons within each species). Therefore, the critical divergence in capture efficiencies occurred between the first and second contact with prey. On average (for both copepod species), single contact encounters had less than a $60 \%$ chance of resulting in a capture, but this probability increased to greater than $90 \%$ when the encounter was extended to 2 or more contacts.

\section{Influence of prey anticipation on predation success}

Mnemiopsis leidyi were not passive during encounters with copepods. Instead, ctenophores responded to contact with copepods by adjusting auricle and lobe positions (Fig. 4). Lobe folding adjacent to the site of contact was frequent. A strong stimulus such as contact with a large copepod of ten resulted in full closure of the lobes, frequently trapping the copepod within the volume of fluid encircled by the closed lobes. Contact on the auricles typically resulted in a reflexive bending of the auricles inward towards the oral tentacles. Reactions by ctenophores to prey were rapid and lobe closure was often swift enough to narrow copepod escape avenues and force a subsequent contact.

Slow motion playback of encounter sequences revealed that ctenophore responses to prey frequently (Acartia tonsa $47 \%$, Oithona colcarva $58 \%$ ) preceded, or anticipated, actual contact between the ctenophore and copepod. These responses by ctenophores in anticipation of contact (anticipatory responses) occurred almost exclusively (A. tonsa 98\%; O. colcarva 96\%) following small swimming motions of the copepod (Fig. 7), often the 'hop and sink' or 'slow swimming' motions described for a number of copepods. In rare circumstances, ctenophores responded to inactive prey 


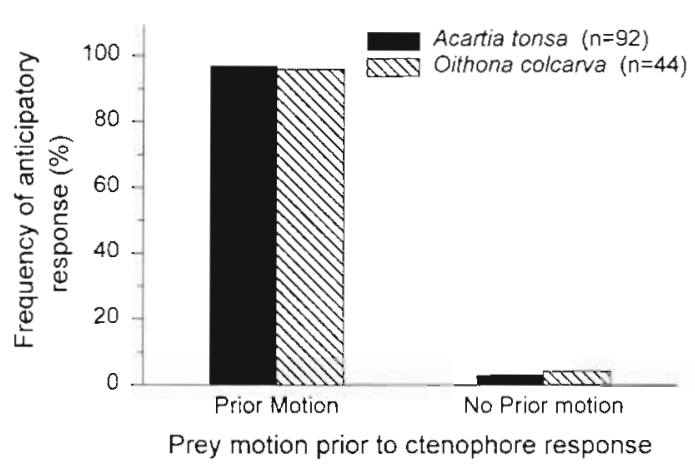

Fig. 7. Relationship between prey (Acartia tonsa and Oithona colcarva) motion and the frequency of anticipatory responses by Mnemiopsis leidyi

prior to contact but only when the prey were no more than $4.0 \mathrm{~mm}$ from the ctenophore's body. Likewise, we observed auricles to bend towards detrital particles entrained in the auricular flow field, but this was uncommon.

Although motion by the copepod prey appeared necessary to initiate anticipatory responses, copepod motions were often not sufficient to initiate anticipatory responses. A total of $30 \%$ of encounters with each copepod species included copepod motions prior to contact but did not result in anticipatory responses by ctenophores. Therefore, motion by copepods appeared to be necessary, but not always sufficient, to initiate anticipatory responses.

Encounters involving anticipatory responses had significantly higher capture efficiencies than encounters without anticipatory responses for both prey types $\left(\chi^{2}\right.$. $p<0.001$ for both prey species, Fig. 8). Overall capture efficiency of encounters with anticipatory responses by ctenophores to Oithona colcarva was higher (93\%) than that of Acartia tonsa ( $86 \%$; Fig. 8), but the difference between species was not significant $\left(\chi^{2}, p=\right.$ $0.216)$. Likewise, capture efficiencies of encounters without anticipatory responses (A, tonsa $63 \%$; O colcarva $59 \%$ ) were not significantly different between the 2 species of copepod prey $\left(\chi^{2}, p=0.721\right)$. Therefore, anticipatory responses by ctenophores influenced capture efficiency similarly between the 2 different prey species.

The positive influence of anticipation upon capture success was not due to an increase in efficiency of capture surfaces accompanying anticipation. Retention rates for 1 - or 2 -contact encounters (which include the majority of captures) were not significantly different between encounters with or without anticipatory responses for either prey species $\left(\chi^{2}, p>0.3\right.$ for Acartia tonsa, $\mathrm{p}>0.5$ for Oithona colcarva; Fig. 9). Therefore, higher retention rates at contact did not explain the higher capture efficiencies of anticipatory encounters.

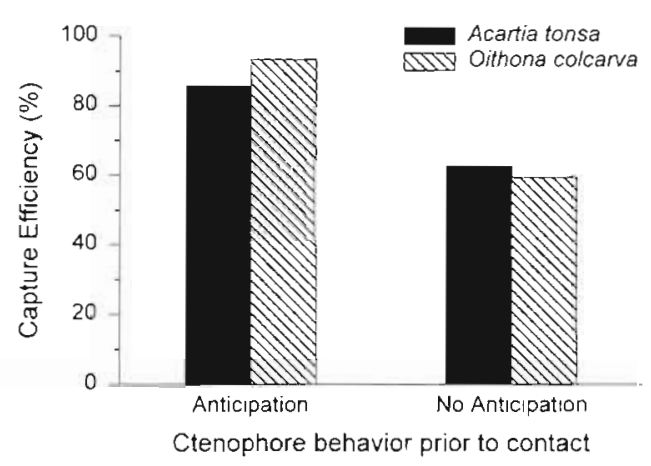

Fig. 8. Effect of anticipatory responses on capture efficiencies of the ctenophore Mnemiopsis leidyi encountering the copepods Acartia tonsa and Oithona colcarva

For both copepod species, the critical factors affecting capture efficiency differences between anticipatory and non-anticipatory encounters were the escape and continuation rates following the first contact. Escape rates following the first contact were significantly lower when an anticipatory response preceded
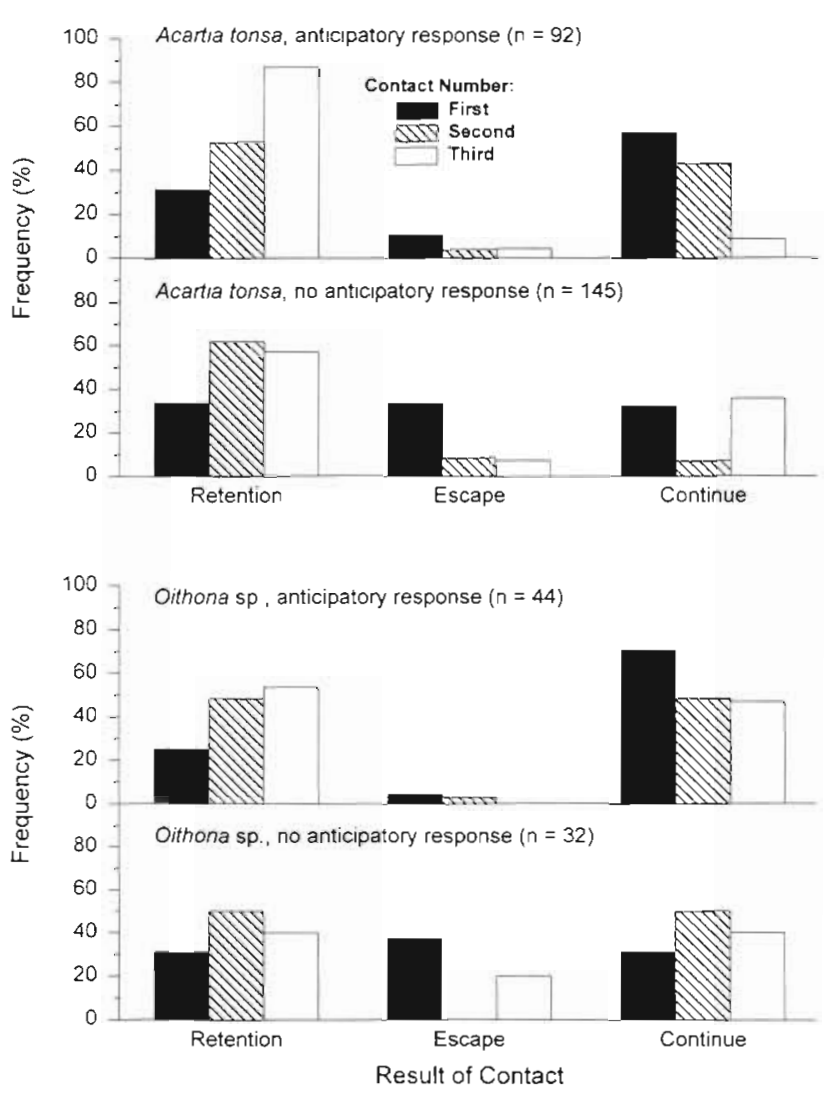

Fig. 9. Contact-specific patterns of encounters with and without anticipatory for responses to the copepods Acartia tonsa (top 2 panels) and Oithona colcarva (bottom 2 panels) encountering the ctenophore Mnemiopsis leidyi 
the contact $\left(\chi^{2}, p<0.001\right.$ for both prey species; Fig 9$)$ There were no significant differences for either prey species in escape rates for the second and third contacts when ctenophores anticipated the copepod, compared to when there was no anticipation. Therefore, the influence of anticipation on escape rates was shortlived and affected only the outcome of the first contact. Continuation rates the proportion of prey which was not captured nor which escaped, but which continued subsequent contacts with the ctenophore) were significantly higher $\left(\chi^{2}, p<0.001\right.$ for both prey species) following the first contact when encounters involved anticipatory responses. With 1 exception, an-ticipation did not affect continuation rates following the second and third contacts. The exception occurred following the third contact for Acartia tonsa, when continuation rates showed a weakly significant decline $\left(\chi^{2}, \mathrm{p}=\right.$ 0.042 ) in anticipatory relative to non-anticipatory encounters (Fig. 9). In this case, few copepods survived a third contact $(96 \%$ of the captures had already occurred) and continuation rates were low. Therefore, the differences in escape and continuation rates between anticipatory and non-anticipatory encounters were limited essentially to the first contact. By the second contact, the advantages accompanying anticipatory responses had declined in importance relative to non-anticipatory encounters.

By extending encounters past the initial contact, anticipation shifted the proportions of single and multiple contact encounters achieved by ctenophores. Whereas encounters without anticipatory responses most often consisted of only a single contact, anticipatory responses were most often followed by multiple contact encounters (Fig. 10). The difference in the

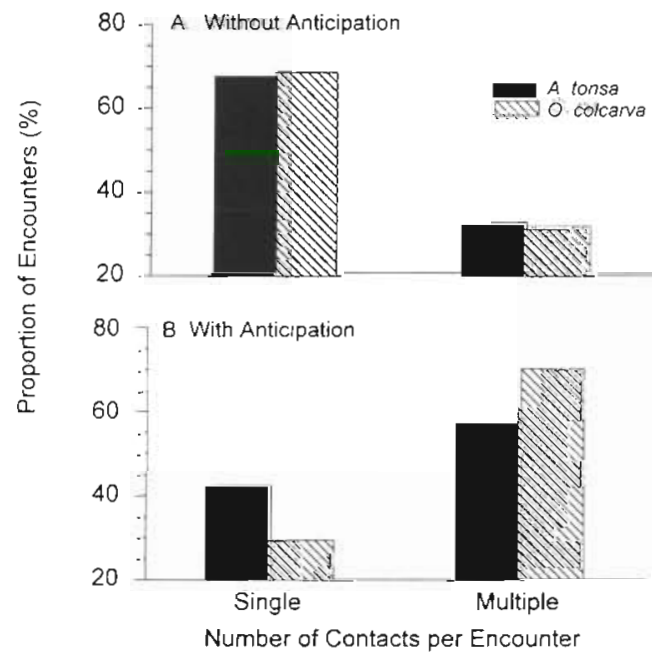

Fig. 10. Proportion of single and multiple contact encounters between the copepods Oithona colcarva, Acartia tonsa and the ctenophore Mnemiopsis leidyi which occurred (A) without and (B) with anticipation of contact proportions of multiple contact encounters following anticipatory responses was significant for both copepod species $\left(\chi^{2}, \mathrm{p}<0.01\right)$. The shift to multiple contacts, combined with the higher capture efficiencies characterizing multiple contact encounters, caused the increase in overall capture rate of anticipatory relative to non-anticipatory encounters.

\section{DISCUSSION}

\section{Variable mechanísms of copepod encounter}

The predominant contact sites of late stage copepod that we observed were the interior surfaces of the oral lobes of Mnemiopsis leidyi. This parallels the observations of Reeve \& Walter (1978) for M. mccradyi, and, more generally, for other lobate ctenophores such as Bolinopsis infundibulum (Schulze-Robbecke 1984) and Leucothea multicornis (Harbison et al. 1978, Hamner et al. 1987).

The means by which encounters originated differed between copepod species. Ciliary currents were effective at entraining and carrying Oithona colcarva near Mnemiopsis leidyi's capture surfaces, but ciliary flow was not effective at entraining Acartia tonsa. Instead, $M$. leidyi depended upon $A$. tonsa swimming into contact with the interior surface of the oral lobes. The different mechanisms of encounter initiation acted simultaneously during feeding upon a mixed assemblage of copepods

In situ studies of prey selection by Mnemiopsis mccradyi, a congener of $M$. leidyi, have demonstrated positive selection for calanoid copepods such as Acartia tonsa relative to cyclopoid copepods such as Oithona colcarva (Larson 1987). Likewise, laboratory feeding studies have shown similar prey selection patterns (Kremer 1979). Our data suggest that, rather than resulting from an inability to capture cyclopoid copepods or an active rejection following capture (we observed no such phenomenon), $M$. leidyi's selection patterns probably resulted from differential encounter rates with alternative prey (Larson 1987, Waggett \& Costello 1999). Even at approximately equal prey densities, flow field entrainment of the less actively swimming cyclopoid $O$. colcarva yielded fewer encounters per unit time than those resulting from direct swimming encounters of the more actively swimming calanoid, $A$. tonsa. These encounter rate differences alone could determine different selection rates because capture efficiencies were not significantly different for the 2 copepod species. This basic distinction between encounter mechanisms probably extends as well to non-motile prey such as fish eggs or slow-swimming prey such as veliger larvae (Waggett \& Costello 1999). 


\section{Ctenophore detection and response to prey}

Encounter sequence grouping in this analysis depended upon the initial observation that retention and capture efficiencies were not significantly different between individual ctenophores. The contact orientation data suggest a qualification of this observation: differences between individual lobate Mnemiopsis leidyi may exist, but these differences are overshadowed by the variability in retention rates due to copepod approach orientation. In a 3-dimensional medium, such as the planktonic environment, copepods can approach from any direction with any body orientation. Overall copepod retention rates by the lobes are low because anterior contacts, characterized by low retention rates, are the dominant orientation at which copepods swim into the ctenophore's lobes. Ventral contacts entangle the copepod's swimming legs and, probably because thrust during escape swimming is generated by these limbs (Morris et al. 1990), escape rates from ventral contacts are low. Posterior contacts also have high retention rates but vary in importance depending upon the species of copepod prey.

These observations indicate that feeding by lobate ctenophores has evolved within the context of a probabilistic dilemma. Variation in ctenophore behavior can do little to influence the contact orientation of incoming copepod prey, and the highest probability is for an orientation at initial contact unfavorable for retention of copepod prey. However, ctenophore behavior can influence subsequent capture probability should the first contact fail to retain the copepod. There is good reason for Mnemiopsis leidyi to evolve behaviors affecting subsequent contacts because retention failure at first contact is the rule (Acartia tonsa $63 \%$, Oithona colcarva $72 \%$; no significant differences with or without anticipation responses for either species) rather than the exception in these encounters. The majority of escapes occur in single contact encounters and overall capture efficiencies are significantly lower for single than multiple contact encounters.

The probabilistic dilemma faced by Mnemiopsis lei$d y i$ is partially resolved by the behavioral response of these ctenophores during encounters with prey. Rather than passively absorbing contact with prey, $M$. leidyi actively responded via a variety of lobe motions. By so doing, escape routes were reduced or eliminated for copepods which were not retained during the initial contact. This led to a higher number of subsequent contacts and increased the probability of a favorable contact orientation within an encounter. As a result, capture efficiency jumped significantly, to over $90 \%$, for all encounters with more than 1 contact. However, the critical step governing overall capture efficiency was that of parrying an encounter to a second contact if the first contact failed to retain a copepod.

Anticipatory responses significantly boosted the rates at which encounters that failed to retain a copepod during the first contact continued to a second contact. Anticipatory responses allow positioning of lobes prior to contact, before the copepod's escape response begins. In the high-speed microenvironment of copepod escape reactions, that slight temporal advantage is highly influential. Although retention rates were not influenced by anticipatory responses, early positioning of lobes decreased escape rates and increased encounter continuation to multiple contacts characterized by significantly increased capture efficiencies. The stimuli eliciting anticipatory responses appear to have been physical displacements of the fluid surrounding swimming copepods. These stimuli are more subtle, but still of the same mechanical nature, as actual physical contact with prey. In this respect, anticipation responses can be viewed as an elaboration of the basic responsivity of lobate Mnemiopsis leidyi to contact with copepod prey. Although mechanosensitivity of ctenophores has rarely been considered in previous reports, Horridge (1965) described non-motile sensory cilia of the lobate ctenophore Leucothea multicornis which detected vibrations of small objects near the ctenophore. Finger-like projections of the external body wall containing these cilia extended towards copepods swimming nearby. That report demonstrates that $M$. leidyi is not unique among ctenophores in its mechanosensory abilities. In fact, prey detection via mechanosensory cues may be widespread among lobate ctenophores and, as with $M$. leidyi, significantly affect feeding success.

\section{Hydrodynamic environment and prey detection}

Increased capture efficiencies accompanying anticipatory responses demonstrate the evolutionary advantages of detection and response to prey motion. However, muscle contractions and loss of capture surface availability during lobe closure entail energetic expenses that may set limits to the advantages of responding to mechanical disturbances. One way to optimize the advantages of anticipatory responses would be to limit the range of stimuli to which Mnemiopsis leidyi respond. This would minimize unproductive responses to inappropriate mechanical stimuli. Indeed, anticipatory responses did not accompany all prey motions, indicating that prey motion was necessary, but not sufficient, to elicit anticipatory lobe responses. Subsequent work in progress indicates that small prey (Acartia tonsa nauplii), presumably creating small fluid disturbances during swimming, rarely elicit 
anticipatory lobe responses. It is possible that $M$. leidyi optimizes the advantages of prey anticipation by selectively responding to only that range of stimuli resembling fluid disturbances of appropriate prey. Prey which are either too small or slow-swimming to create a sufficient disturbance may be entrained in the auricular flow and captured on tentillae (Waggett \& Costello 1999). The energetic expense of lobe responses may be unnecessary for these prey. In contrast, large disturbances may be due to motions by swimmers too large for capture, such as large fish, or eddies due to ambient turbulence. Either of the latter may interfere with the detection of appropriate prey. Interestingly, lobate ctenophores have long been known to close their lobes and swim away from large mechanical disturbances (Hamner et al. 1987) and to avoid highly mixed surface waters (Miller 1974, Kremer \& Nixon 1976). Avoidance of small scale turbulence by $M$. leidyi is unexpected considering that an ambush predator should benefit from elevated encounter rates in turbulent flows (Rothschild \& Osborn 1988). However, turbulence avoidance may be an appropriate behavioral response for a predator reliant upon detection of small mechanical disturbances that are unresolvable within the hydrodynamic noise created by strong turbulence. The spectrum of stimuli to which $M$. leidyi responds and the integration of these responses into the ctenophore's broader behavioral repertoire have not been determined. However, the importance of $M$. leidyi and, more generally, lobate ctenophores as planktonic predators implies that factors influencing their perception of prey may have significant impacts on planktonic trophic pathways.

Acknowledgements. The authors are grateful to S. Colin, P Kremer. R. Rapoza, B. Schulte, A. Selle, J. R. Strickler, C. Suchman and B. Sullivan for discussion and comments on this manuscript. Financial support for this research was provided by the National Science Foundation IOC:E 9103309 and OCE9820172 to J.H.C.)

\section{LITERATURE CITFD}

Bishop JW (1967) Feeding rates of the ctenophore, Mnemiopsis leidyi. Chesapeake Sci 8:259-261

Burrell VG, Van Engel WA (1976) Predation by and distribution of a ctenophore, Mnemiopsis leidyi A. Agassiz, in the York Estuary. Estuar Coast Mar Sci 4:235-242

Costello JH, Colin SP (1994) Morphology, fluid motion and predation by the scyphomedusa Aurelia aurita, Mar Biol $121: 327-334$

Editorial responsibility: Kenneth Sherman (Contributing Editor), Narrangansett, Rhode Island, USA
Deason EE Smayda TJ (1982) Ctenophore-zooplankton-phytoplankton interactions in Narragansett Bay, Rhode Island, USA, during 1972-1977. J Plankton Res 4. 203-217

Gerritsen J, Strickler JR (1977) Encounter probabilities and community structure in zooplankton: a mathematical model. J Fish Res Board Can 34:73-82

Hamner WM, Strand SW, Matsumoto GI, Hamner PP (1987) Ethological observations on foraging behavior of the Ctenophore Leucothea sp. in the open sea. Limnol Oceanogr 32:645-652

Harbison GR, Madin LP, Swanberg NR (1978) On the natural history and distribution of oceanic ctenophores. Deep-Sea Res 25:233-256

Horridge GA (1965) Non-motile sensory cilia and neuromuscular junctions in a ctenophore independent effector organ. Proc R Soc Lond B 162:333-350

Hulsizer EE (1976) Zooplankton of lower Narragansett Bay, 1972-1972. Chesapeake Sci 17:260-270

Hyman LH (1940) The invertebrates, Vol 1. Protozoa through Ctenophora. McGraw-Hill, New York

Kremer P (1979) Predation by the ctenophore Mnemiopsis leidyi in Narragansett Bay, Rhode Island. Estuaries 2: $97-105$

Kremer P, Nixon S (1976) Distribution and abundance of the ctenophore, Mnemiopsis Jeidyi, in Narragansett Bay. Estuar Coast Mar Sci 4:627-639

Larson. RJ (1987) In situ feeding rates of the ctenophore Mnemiopsis mccradyi. Estuaries 10:87-91

Madin LP (1988) Feeding behavior of tentaculate predators: in situ observations and a conceptual model. Bull Mar Sci $43: 413-429$

Miller RJ (1974) Distribution and biomass of an estuarine ctenophore population, Mnemiopsis leidyi (A. Agassiz). Chesapeake Sci 15:1-8

Morris MJ, Kohlage K. Gust G (1990) Mechanics and energetics of swimming in the small copepod Acanthocyclops robustus (Cyclopoida). Mar Biol 107:83-91

Mountford K (1980) Occurrence and predation by Mnemiopsis leidyi in Barnegat Bay, New Jersey. Estuar Coast Mar Sci 10:393-402

Reeve MR, Walter MA (1978) Nutritional ecology of ctenophores-a review of recent research. Adv Mar Biol 15: $249-287$

Reeve MR, Walter MA, Ikeda T (1978) Laboratory studies of ingestion and food utilization. in lobate and tentaculate ctenophores. Limnol Oceanogr 23:740-751

Rothschild BJ, Osborn. TR (1988) The effect of turbulence on planktonic contact rates. J Plankton Res 10:465-474

Schulze-Robbecke AC (1984) Functional morphology of Bolinopsis infundibulum (ctenophore). Helgol Meeresunters 38:47-64

Strickler JR (1975) Swimming of planktonic Cyclops species (Copepods, Crustacea): pattern, movements and their control. In: Wu TYT, Brokow CJ, Brennon C (eds) Swimming and flying in nature, Vol 2. Plenum Press, New York, p 599-613

Waggett R, Costello JH (1999) Capture mechanisms used by the lobate ctenophore, Mnemiopsis leidyi preying on the copepod Acartia tonsa. J Plankton Res 21:2037-2052

Submitted: January 15, 1999; Accepted: June 28, 1999

Proofs received from author(s): December 20, 1999 